\title{
Assessment of agro-morphological, physiological and yield traits diversity among tropical rice
}

\author{
Naqeebullah Kakar ${ }^{1}$, Raju Bheemanahalli ${ }^{1}$, Salah Jumaa ${ }^{1,2}$, Edilberto Redoña ${ }^{3}$, Marilyn Warburton ${ }^{4}$, Kambham R \\ Reddy ${ }^{\text {Corresp. } 1}$ \\ ${ }^{1}$ Deaprtment of Plant and Soil Sciences, Mississippi State University, Mississippi State, Ms, United States \\ 2 Field Crops Department, Tikrit University, Tikrit, Iraq \\ 3 Delta Research and Extension Center, 82 Stoneville Road, Mississippi State University, Stoneville, MS 38776, United States \\ 4 Corn Host Plant Resistance Research Unit, Crop Science Research Laboratory, USDA-ARS, Mississippi State, MS 39762, United States \\ Corresponding Author: Kambham R Reddy \\ Email address: krreddy@pss.msstate.edu
}

Rice (Oryza sativa L.) is an essential staple food crop, but the per acre average rice yield is less than its substantial potential in many countries. Rice breeders and growers would benefit from a robust ideotype to understand morpho-physiological and yield-related traits better. Here, seventy-four new rice genotypes were phenotyped over two years for their gas exchange and yield potential-related traits under Mississippi rice-growing conditions. A wide range of variability was observed among genotypes for all measured traits. Detailed phenotyping of rice genotypes revealed two key relationships that function together to contribute to yield potential under the southern US climate. The first one, grain yield, grain number, and spikelet fertility, showed considerable correlation ( $r=0.45$ to $0.79, p<0.001$ ) to harvest index. Conversely, days to anthesis had a high and negative correlation with harvest index $(r=-0.79, p<0.001)$, which suggests that selection for short duration genotypes with efficient partitioning could improve the yields under southern US climatic conditions. Additive response index revealed a higher positive association with yield traits $\left(R^{2}=0.59\right)$ than physiological $\left(R^{2}=0.28\right)$ and morphological traits $\left(R^{2}=0.21\right)$. Compared with the commercial genotype Rex, $21.6 \%$ and $47.3 \%$ of the rice genotypes had a higher gas exchange and yield response scores. IR08A172, IR07K142, and IR07F287 were ranked as high performers in physiological and yield response indices. Our study highlights that selection for short-duration yield-related traits with efficient sink capacity traits is desirable for future breeding programs. 
1 Assessment of agro-morphological, physiological and yield 2 traits diversity among tropical rice

3 Naqeebullah Kakar ${ }^{1}$, Raju Bheemanahalli' ${ }^{1}$, Salah Hameed Jumaa ${ }^{1,2}$, Edilberto Diaz Redoña ${ }^{3}$,

4 Marilyn Warburton ${ }^{1}$, and Kambham Raja Reddy ${ }^{1 *}$

1. Department of Plant and Soil Sciences, Mississippi State University, Mississippi State, MS 39762, USA

2. Field Crops Department, Tikrit University, Tikrit 009642, Iraq

3. Delta Research and Extension Center, Mississippi State University, 82 Stoneville Road, Stoneville, MS 38776, USA

4. Corn Host Plant Resistance Research Unit, Crop Science Research Laboratory, USDAARS, Mississippi State, MS 39762, USA

Corresponding Author:

13 Kambham Raja Reddy

14 Department of Plant and Soil Sciences

15 Mississippi State University, Mississippi State, MS 39762, USA

16 Email address: krreddy@pss.msstate.edu 


\section{Abstract}

18 Rice (Oryza sativa L.) is an essential staple food crop, but the per acre average rice yield is less 19 than its substantial potential in many countries. Rice breeders and growers would benefit from a 20 robust ideotype to understand morpho-physiological and yield-related traits better. Here, 21 seventy-four new rice genotypes were phenotyped over two years for their gas exchange and 22 yield potential-related traits under Mississippi rice-growing conditions. A wide range of variability was observed among genotypes for all measured traits. Detailed phenotyping of rice genotypes revealed two key relationships that function together to contribute to yield potential under the southern US climate. The first one, grain yield, grain number, and spikelet fertility, showed considerable correlation $(r=0.45$ to $0.79, p<0.001)$ to harvest index. Conversely, days to anthesis had a high and negative correlation with harvest index $(r=-0.79, p<0.001)$, which suggests that selection for short duration genotypes with efficient partitioning could improve the yields under southern US climatic conditions. Additive response index revealed a higher positive association with yield traits $\left(R^{2}=0.59\right)$ than physiological $\left(R^{2}=0.28\right)$ and morphological traits $\left(R^{2}=0.21\right)$. Compared with the commercial genotype Rex, $21.6 \%$ and $47.3 \%$ of the rice genotypes had a higher gas exchange and yield response scores. IR08A172, IR07K142, and IR07F287 were ranked as high performers in physiological and yield response indices. Our study highlights that selection for short-duration yield-related traits with efficient sink capacity traits is desirable for future breeding programs.

Subjects Agricultural Science, Plant Science

Keywords Rice, phenotypic diversity, morpho-physiological, yield traits, early and late maturity, 40 individual and total response indices. 


\section{Introduction}

43

44

45

46

47

48

49

50

51

52

53

54

55

56

57

58

59

60

61

62

63

64

65

66

67

68

69

70

71

72

73

74

Rice (Oryza sativa L.) is an important food crop that feeds more than half of the world's population. It is consumed as a staple food in the rice-producing areas of Asia, Africa, and South America. Global rice production has increased considerably from 1.86 to $4.66 \mathrm{t} \mathrm{ha}^{-1}$ over the past six decades (http://www.fao.org/faostat/en/\#data/QC/visualize). Currently, rice is being grown in variable climate conditions in more than 100 countries, on an estimated area of about 163 million ha with 481 million metric tons of annual production. However, the current level of rice productivity is not enough to feed the rapidly increasing global population (Foley et al., 2011; Lesk, Rowhani \& Ramankutty, 2016) and needs to be improved quantitatively and qualitatively to ensure global food security (https://www.yieldgap.org/web/guest/yieldgaps). On the other hand, global rice cropland areas witness yield stagnation or collapse up to 35\% (Ray et al., 2012). With the global population multiplying and projected to reach 10 billion before 2100 , the rice yield gains stagnation in recent years is predicted to have profound implications on the food chain (Ray et al., 2012). There is a need to break these slowing yield trends to minimize negative impacts on global food production.

Morphological and yield-associated traits have frequently been used as a criterion to evaluate phenotypic variability and as the basis for the enhancement of rice-yield potential. In rice, the yield is associated with several component traits ( $\mathrm{Li}$ et al., 2014), including panicle number per unit area, filled grains per panicle, and 1000-grain weight (Yoshida, Satake \& Mackill, 1981; Sakamoto \& Matsuoka, 2008; Mohammadi et al., 2010; Xing \& Zhang, 2010; Huang et al., 2013; Li et al., 2019), and with other traits such as plant height, tillering ability, canopy architecture (Huang et al., 2013), total biomass production (Long et al., 2006) and photosynthetic efficiency (Zhu, Long \& Ort, 2008). Genetic variation in gas exchange and pigment traits have been explored and used in different breeding programs (Zhao et al., 2010; Kondamudi et al., 2016; Haritha et al., 2017). Photosynthesis has been the precondition for a successful breeding program to increase photo-assimilate production in high-yielding genotypes (Haritha et al., 2017). Apart from gas exchange, several plant traits influence leaf photosynthetic rates, such as leaf pigments, water use efficiency, and photosystem (PS) II activity. For example, genotypes with slower Rubisco degradation or stay green trait resulted in a longer duration of photo-assimilation and higher yield (Shin et al., 2020). Along with significant morphological and physiological features, variation at indica subspecies seems to have a rapid life cycle due to earlier senescence traits (Abdelkhalik et al., 2005). In breeding for improved yield potential in rice, direct selection of yieldrelated traits, which are easier to measure precisely than yield itself, have been used as an 
75 effective strategy in many studies when they have a strong correlation with crop yield (Mehetre et al. 1994; Samonte et al. 1998; Kumar et al. 2014). Thus, improving these correlated traits has become a primary objective for rice improvement over the years. However, there are limited studies that have explored the role of physiological parameters for enhancing rice cultivars' grain yield. Although genetic diversity in rice physiology is complex, exploiting the genotypes' genetic potential is critical for identifying yield-enhancing traits under non-stress conditions (Dutta et al. 2013).

In the United States, rice is mainly grown in two distinct regions, i.e., the US Mid-south and the Sacramento Valley in California. Compared with global rice production, rice yield in the US increased several folds (4.5 $\mathrm{tha}^{-1}$ to $8.53 \mathrm{t} \mathrm{ha}^{-1} \mathrm{http}: / /$ ricestat.irri.org:8080/wrs) over the last two decades due to the utilization of different germplasm pools and improved management practices (McKenzie et al., 2015). However, the increasing frequency of storms and floods, temperature extremes, drought events, and rapid urbanization coupled with increasing population are still significant constraints to ensuring food security (Du et al., 2015). Thus, raising yield potential under non-stress conditions has been a fundamental goal of rice breeding efforts (Peng et al., 2008; Guan et al., 2010). Rice producers in the USA prefer short- to medium-duration genotypes, which enable mechanized harvesting. Despite, the increase in demand for short-duration rice genotypes, physiological and genetic improvement has been slow (Won et al., 2020). The lack of stable, high-yielding short-duration varieties would soon becoming a major limitation in achieving maximum yield potential in the USA rice production system. Because of the narrow planting window in the US, late-planted rice tends to be lower yielding as it experiences long daylength along with other in-season drought or increased disease pressure and fall frost during crop maturity. On the other hand, spring cold impacts seedling emergence if rice is planted too early. Due to variability in challenges at the start and end of the growing season, there is a need to identify suitable rice genotypes for a short growing window. Thus, developing or identifying high-yielding, short-duration rice genotypes with efficient source-sink capacity or high harvest index is critical.

Understanding the relationship between growth and developmental, physiological, and yield-related traits and other contributing characters helps maximum breeding gain from a selection. The additive vigor indices are a reliable method of assessing the growth rate and development of genotype performance under fluctuating environmental conditions (Reddy et al., 2021). Here, we show how the additive response index can help identify relationships between morpho-physiological and yield-related traits of rice genotypes under non-stress conditions. We phenotyped a panel of 74 tropical rice genotypes over two years for gas 
109

110

111

112

113

114

115

116

117

118

119

120

121

122

123

124

125

126

127

128

129

130

131

132

133

134

135

136

137

138

exchange, yield, and yield-related traits to identify short-duration high-yielding rice for the midsouthern US rice growing climate. The specific objectives of this study are to (1) evaluate variation in gas exchange and pigments traits at the reproductive stage, (2) assess the phenotypic performance of new rice genotypes for yield potential traits, (3) develop a method to determine additive index variability among rice genotypes, and (4) identify high yielding shortduration rice genotype/s with greater partitioning efficiency.

\section{Materials \& Methods}

\section{Germplasm, experimental setup, and growth conditions}

Plant material comprised of 74 rice breeding lines (mainly belonging to indica subspecies but including two local tropical japonica cultivars from the Mid-South US for comparison) obtained from the International Rice Research Institute (IRRI) in Los Banos, Philippines (Table S1). An experiment was conducted at the Environmental Plant Physiology Laboratory, Mississippi State

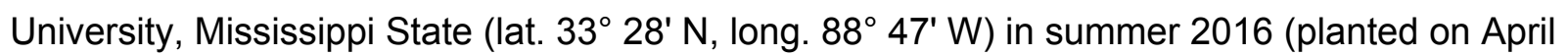
29) and 2017 (planted on April 24), in a randomized complete block design (RCBD) with five replications and 74 rice breeding lines. A total of 370 PVC pots (5 pots per genotype) with dimensions of 6" diameter by 24" high was filled with pure sand as a soil medium and arranged in the natural sunlight for sowing. Initially, six seeds were sown per pot for each genotype, thinned to one seedling per pot for each genotype 12 days after sowing (DAS). A drip irrigation system was installed to irrigate the experiment with freshwater until seedling emergence; once seedlings emerged, they were irrigated with Hoagland nutrition Solution three times daily (8:00 am, 12:00 pm 5:00 pm) to avoid any confounding effect of drought stress and nutrient deficiency. Weather data for the growing seasons were obtained from the National Water and Climate Center (https://www.wcc.nrcs.usda.gov/). Average ambient minimum and maximum air temperature during the cropping window were $19.9{ }^{\circ} \mathrm{C}(\mathrm{SD} \pm 4.5)$ and $30.8^{\circ} \mathrm{C}(\mathrm{SD} \pm 3.9)$ in 2016 , and $18.5^{\circ} \mathrm{C}(\mathrm{SD} \pm 3.8)$ and $28.9^{\circ} \mathrm{C}(\mathrm{SD} \pm 2.4)$ in 2017. The corresponding relative humidity $(\mathrm{RH})$ were $85.9 \%(\mathrm{SD} \pm 3.4)$ and 88.4\% (SD \pm 4.6$)$ in 2016 and 2017.

\section{Data collection}

Gas exchange and pigments

Physiological traits including net photosynthesis $\left(\mathrm{Pn}, \mu \mathrm{mol} \mathrm{m} \mathrm{m}^{-2} \mathrm{~s}^{-1}\right)$, stomatal conductance (Cond, mol m-2 $\mathrm{s}^{-1}$ ), leaf transpiration rate $\left(\mathrm{Tr}, \mathrm{mmol} \mathrm{H}_{2} \mathrm{O} \mathrm{m}^{-2} \mathrm{~s}^{-1}\right)$, water use efficiency (WUE, 
$\left.139 \mathrm{mmol} \mathrm{CO}_{2} \mathrm{~mol}^{-1} \mathrm{H}_{2} \mathrm{O}\right)$, chlorophyll fluorescence $\left(\mathrm{Fv}^{\prime} / \mathrm{Fm}\right.$ ') and electron transport rate $(\mathrm{ETR}, \mu \mathrm{mol}$ $140 \mathrm{~m}^{-2} \mathrm{~s}^{-1}$ ) were measured using LI-6400 portable photosynthesis system (LI-COR Inc., Lincoln,

141 Nebraska, USA). A freshly expanded penultimate leaf from each plant was used for taking

142 physiological measurements by using LI-6400. Before taking measurements, the instrument (LI-

143 6400) was set to for photosynthetic photon flux density (PPFD) (1500 $\left.\mu \mathrm{mol} \mathrm{m}^{-2} \mathrm{~s}^{-1}\right)$ based on

144 640-02 LED light source, temperature $\left(30^{\circ} \mathrm{C}\right.$ ) and $\mathrm{CO}_{2}$ concentration (400 ambient $\mathrm{CO}_{2}$ level in

145 the outdoors); whereas leaf water use efficiency was calculated as the ratio of photosynthesis

$146(\mathrm{Pn})$ to transpiration rate $(\mathrm{Tr})$ per plant.

147 Chlorophyll contents (Chl) and carotenoids (car) were measured for all the genotypes by

148 taking the fresh penultimate leaves at the vegetative growth stage (50-60 DAS) of the individual 149 plants from all five replications. Five leaf discs $\left(2.0 \mathrm{~cm}^{2}\right.$ each $)$ were carefully attained from the 150 mid-blade of the fresh leaf without including mid-vein and set in a vial (5-ml) with 5-ml dimethyl 151 sulphoxide (DMSO). The vials were then incubated in a dark chamber at room temperature for $15224 \mathrm{~h}$ to affluence the complete extraction of chlorophyll into the solution. Bio-Rad ultraviolet/VIS 153 spectrophotometer (Bio-Rad Laboratories, Hercules, CA) was used to measure the absorbance 154 of extracts in the polypropylene microtiter plates and estimate the concentrations of carotenoid 155 contents and total chlorophyll (chla+b) as described by (Chapple et al., 1992). The absorbance 156 values at 470,648 , and $663 \mathrm{~nm}$ were used to calculate the concentrations of total chlorophyll 157 contents and carotenoids (Lichtenthaler, 1987).

Agro-morphological traits

159 Days to $50 \%$ seedling emergence $(50 \%$, E) were manually recorded for each genotype when more than three seeds emerged from the soil surface out of the total six seeds grown per pot. Agro-morphological traits included significant growth and developmental traits like tillers number (TN, no. plant $\left.{ }^{-1}\right)$ and plant height $\left(\mathrm{PH}, \mathrm{cm}\right.$ plant $\left.{ }^{-1}\right)$ were measured manually before flowering at the vegetative stage (50-60 days after sowing), and grain filling stage (100-110 DAS). Days to heading or anthesis (DH) refers to the number of days from sowing to the first panicle emergence in each plant. For dry shoot weight $\left(\mathrm{SHW}, \mathrm{g} \mathrm{plant}^{-1}\right)$, plants were harvested and stored in a dryer at $70{ }^{\circ} \mathrm{C}$ for at least $72 \mathrm{~h}$ or until thoroughly dried, and dry weights were recorded for each genotype using a bench weighing balance (Adventure ${ }^{\mathrm{TM}}$, OHAUS Corporation, NJ, USA). 
170 Several yield-related traits were measured, including panicle length plant ${ }^{-1}(\mathrm{PL})$, spikelet

171 numbers panicle ${ }^{-1}$ (SPN), number of grains panicle ${ }^{-1}(\mathrm{GN})$, grain weight panicle $\mathrm{e}^{-1}(\mathrm{GW})$, filled

172 and unfilled grain percentage (GF), and total grain yield plant ${ }^{-1}(\mathrm{GY})$. Panicle length (PL, cm)

173 was manually measured using a ruler (ACE Hardware, Metal ruler) as the distance (cm) from

174 the panicle neck node base to the last spikelet's tip of the same panicle. Five panicles were

175 collected from each rice plant as representative samples, labeled, and air-dried in the laboratory

176 for approximately two weeks to measure SPN, GN, and GW. For shoot dry weight (SHW, g

177 plant $^{-1}$ ), leaves and stems of individual plants were harvested, dried, and weighted. Total grain

178 yield (GY, g plant ${ }^{-1}$ ) was measured as the sum of the entire grains from all the individual plants

179 of the same genotype in five replications. The spikelet fertility in the percentage (SF, \%) was

180 measured after separating the filled grains from the unfilled grain in all genotypes. Harvest index

181 (HI) was calculated as a ratio of grain yield and biological yield (Amanullah \& Inamullah, 2016).

\section{Statistical analysis}

183

184

185

186

187

188

189

190

191

192

193

194

195

196

$$
\mathrm{IRI}=\mathrm{Vx} / \mathrm{Vm}
$$

197 For the additive response index (ARI), all the individual indices of response traits for each rice 198 genotype at vegetative, grain filling stages, and final harvest were summed (Eq. 2). 
199 ARI $=\left(\frac{\text { Pnx }}{\text { Pnm }}\right)+\left(\frac{\text { Condx }}{\text { Condm }}\right)+\left(\frac{\text { Trx }}{\text { Trm }}\right)+\left(\frac{\text { WUEx }}{\text { WUEm }}\right)+\left(\frac{\text { Fv' }^{\prime} / F^{\prime} x}{\text { Fv' }^{\prime} / F^{\prime} m}\right)+\left(\frac{\text { ETRx }}{\text { ETRm }}\right)+\left(\frac{\text { Chlx }}{\text { Chlm }}\right)+\left(\frac{\text { Carox }}{\text { Carom }}\right)+\left(\frac{\text { DEx }}{\text { DEm }}\right)+$

$200\left(\frac{\mathrm{DHx}}{\mathrm{DHm}}\right)+\left(\frac{\mathrm{PHx}}{\mathrm{PHm}}\right)+\left(\frac{\mathrm{TNx}}{\mathrm{TNm}}\right)+\left(\frac{\mathrm{SHWx}}{\mathrm{SHWm}}\right)+\left(\frac{\mathrm{PLx}}{\mathrm{PLm}}\right)+\left(\frac{\mathrm{SPNx}}{\mathrm{SPNm}}\right)+\left(\frac{\mathrm{GWx}}{\mathrm{GWm}}\right)+\left(\frac{\mathrm{GNx}}{\mathrm{GNm}}\right)+\left(\frac{\mathrm{SFx}}{\mathrm{SFm}}\right)+\left(\frac{\mathrm{GYx}}{\mathrm{GYm}}\right)+\left(\frac{\mathrm{HIx}}{\mathrm{HIm}}\right)$

201

[Eq. 2]

202

203 The ARI (on average ARI of 74 genotypes $=21.5$ ) and standard deviation $(S D=2)$ were then

204 used to classify the 74 rice genotypes into potential highly desirable ones (high), and

205 moderately desirable (Moderately High), undesirable (Moderately Low), and highly undesirable 206 ones (Low) using the following equations.

207 High $=$ genotypes with ARI values $>23.5$

[Eq. 3]

208 Moderately High $=$ genotypes with ARI values between $<23.5$ and $>21.5$ [Eq. 4]

209 Moderately Low $=$ genotypes with ARI values between $<21.5$ and $>19.5 \quad$ [Eq. 5]

210 Low $=$ genotypes with $\mathrm{ARI}$ values $<19.5$

211 The top-ranking genotypes for physiological and yield traits under well-watered conditions were 212 identified. Graphs for the relationship between morpho-physiological and yield-related traits 213 were plotted using Sigma Plot 13 (Systat Software Inc., San Jose, CA).

\section{Results and Discussion}

215 Phenotypic variation

216 Complex physiological and biochemical processes control plant growth and development. Each developmental phase involves various metabolic changes and is affected by diurnal factors such as light, temperature, and day length. Rice growing seasonal variation in the US is different from other more tropical regions such as Africa, India, and the Philippines due to the

220 onset and offset cold-weather windows. This study characterized variation in 74 genotypes of $O$. sativa obtained from IRRI for morpho-physiological and yield-related traits over two years under non-stress conditions. A list of traits measured and their ranges are provided in Table 1. The variation in physiological, morphological, and yield-related traits differed significantly among genotypes $(p<0.001)$. Most of the traits were not affected ( $p>0.05)$ by Year $(2016$ and 2017$)$ and

225 Genotype by Year interactions except for plant height, days to heading, and tiller number (Table

226 1). Due to the non-significant difference in mean average temperatures $\left(24.4 \pm 4.0^{\circ} \mathrm{C}\right.$ in 2016 227 and $23.4 \pm 2.9^{\circ} \mathrm{C}$ ) and relative humidity ( $85.6 \%$ in 2016 and $88.4 \%$ in 2017) between years, 228 the two years data points were combined for further analysis. 
Under non-stress conditions, the average number of days to $50 \%$ emergence (when

230

231

232

233

234

235

236

237

238

239

240

241

242

243

244

245

246

247

248

249

250

251

252

253

254

255

256

257

258

259

260

\section{Principal component and correlation analysis}

Principal component analysis (PCA) was performed to explore the relationship between traits and rice genotypes under non-stress conditions (Fig. 1A-C). The first two principal components (PC) cumulatively explained $41.7 \%$ (PC1: $25.6 \%$ and PC2: $16.2 \%$ ) of the total phenotypic variation (Fig. 1A). PC1 contributed more towards yield and related traits to the separation of rice genotypes and captured the variability for harvest index (16.4\%), grain weight (15.4\%), grain number (12.3\%), days to heading (10.1\%), and grain yield (10\%). PC2 explained 16.2\% of the variation between genotypes, mostly contributed by physiological traits such as $\mathrm{Pn}(22.7 \%)$, Chl (17.1\%), Caro (12.6\%), and $\operatorname{Tr}(11.3 \%)$. PC1 showed a positive association with GY (0.7), GW (0.87), GN (0.77), HI (0.89), and SF (0.47). In contrast, the number of days to heading ($0.70)$ and SHW at maturity (-0.52) were negatively correlated with PC1. Gas exchange parameters such as $\mathrm{Pn}$ (0.83), Chl (0.82), Caro (0.62), and $\operatorname{Tr}(0.59)$ were positively associated with PC2 (Fig. 1B). A 2D scatter plot of factor loading values separated 74 genotypes into four different groups (Fig. 1C) A positive relationship was found between DH and SHW ( $r=$ $0.58, p<0.001)$. At the same time, $\mathrm{DH}$ showed strong and negative correlations $(r=-0.44$ to $0.79, p<0.001$ ) with most of the yield-related variables (Fig. 2). Similarly, SHW was negatively correlated with GW ( $r=-0.44, p<0.001)$, SF $(r=-0.39, p<0.001)$, and $\mathrm{HI}(r=-0.70, p<0.001)$, which indicates that genotypes with a longer life span are associated with lower yield potential (Fig. 2) under the mid-south US climatic conditions. Although early flowering genotypes have a short period of vegetative growth, the reproductive and grain filling stages have been reported to be similar for rice (Kropff, Laar \& Matthews, 1994). These observations indicate that selection of 
261 short-duration rice genotypes with no plateauing in yield would offer multiple advantages

262 compared with long-duration rice genotypes in the southern US growing season.

263 Rice genotypes were differentiated into four groups, separating high and low performers 264 and other combinations based on the factor scores of PC1 and PC2. As shown in the biplot (Fig. 265 1C), the vector's direction and angle represent the relationships among traits. The dispersion of 266 genotypes in the same direction as the vectors helped group them with similar physiology and 267 yield traits. Rice genotypes with better physiology and higher-yielding traits might become an 268 essential resource for rice breeders. As suggested by the PCA, 74 rice genotypes were 269 classified into four groups. Group 1 and 2 included 24 rice genotypes, and group 3 included 17, 270 and group 4 had 15 genotypes (Fig. 1C).

272 There were significant differences between PC-derived groups for gas exchange traits (Fig. 3A$273 \mathrm{H}$ ). The mean of $\mathrm{Pn}$ in group 1 (IR08N136) and group 4 (IR65482) were significantly $(P<0.05)$ 274 higher than that of group 2 (IR93323) and group 3 (CT19561). On average, genotypes from 275 group 1 had significantly greater stomatal conductance (IR10N230, Fig. 3B), $\operatorname{Tr}$ (IR78221, Fig. 276 3C), WUE (IR08N136, Fig. 3D), Chl (IR07K142, Fig. 3G), and Caro (IR07K142, Fig. 3H) than 277 genotypes from group 3. Further, iWUE varied significantly $(\mathrm{p}<0.05)$ among the four groups. On 278 average, group 1 (IR08N136 and IR09L337) and group 4 (IRRI152 and IR65482) genotypes 279 had significantly greater iWUE compared to group 2 (IR09L324) and group 3 (CT18372).

280 However, Fv'/Fm' and ETR were not different among groups except for ETR in group 3 (Fig. 3D281 F). Like Pn, Chl and Caro were also significantly higher in group 1 and group 4 than the other 282 two groups (Fig. 3G, H). The physiological characterization of plants helps assessment of the 283 genetic diversity within the germplasm pool. Variability in leaf chlorophyll content (Prasad \& 284 Djanaguiraman, 2011; Reddy et al., 2021), carotenoids, and relative injury (Zafar et al., 2018) 285 have been previously used as screening tools to identify vigorous germplasm (Sheshshayee et 286 al., 2006; Syed Shah, Rasmus Houborg \& Matthew McCabe, 2017; Singh et al., 2018).

287 Similarly, chlorophyll and leaf area are crucial in determining the yield (Lu et al., 1994; Anyia, 288 2004; Kikuchi et al., 2017; Won et al., 2020), as higher densities of chlorophyll per unit leaf area 289 have been observed in thicker leaves, enhancing the photosynthetic capabilities (Craufurd et al., 290 1999) of plants resulting in the vigorous and productive crop. Overall, our results suggested that 291 the group 1 and 4 rice genotypes are associated with better photosynthetic efficiency and high 
292 iWUE, which can be selected for biomass improvement (Placido et al., 2013; Vikram et al., 293 2016).

294

295

296

297

298

299

300

301

302

303

304

305

306

307

308

309

310

311

312

313

314

315

316

317

318

319

320

321

322

Agro-morphological phenotype

The 74 genotypes showed significant variability in days to heading (DH), which is a useful trait because early heading lines mature earlier (Won et al., 2020). Sixteen of the 74 genotypes flowered earlier than control entry Rex. On average, DH was the longest in group 4 (142 d) and group 3 (125 d) genotypes, which may not be suitable for a short growing season. Days to heading was shortest in group 2 (IR49830, $85.3 \mathrm{~d}$ ) and group 1 (IR08A172, 89. $6 \mathrm{~d}$ ), which were $12 \mathrm{~d}$ and $54.4 \mathrm{~d}$ earlier than Rex and the average of group 4 genotypes, indicating that these genotypes may be photoperiod insensitive (Fig. 4A). Greater biomass at flowering coupled with lack of photoperiod sensitivity could boost yield in US mid-south environments, and the negative correlation between $\mathrm{DH}$ and yield suggests opportunities to select high-yielding genotypes from short-duration genotypes. Similarly, the mean values of total tiller number (TN) in group 4 were significantly greater than in group 2 and 1 by 34.5 and 18.5\%, respectively (Fig. 4B). While there was significant genetic variability in $\mathrm{PH}$, it did not differ between PCA-derived groups (Fig. 4C), indicating that the $\mathrm{DH}$ and TN traits interacted less with $\mathrm{PH}$ in this population.

Genotypes with earlier flowering (i.e., group 1 and 2) also had 37.4\% lower mean dry shoot weight (SHW) as compared with group 4 (Fig. 4D). Differences in shoot dry weights are related to other growth and developmental traits, including PH and TN. Genotype IRRI152 had both the highest SHW and greatest plant height, and genotype IR09L179 had the lowest SHW and least number of tillers among all the genotypes. Since similar environmental conditions were observed in both years, the differences in growth and developmental traits, particularly PH and TN, maybe due to the genetic variability among the genotypes. This can be exploited in breeding programs to screen for high-yielding cultivars. At a given growth stage, these parameters are shown to be heritable and stable for evaluating rice genotypes (Peng et al., 2008). Taller rice plants compete with weeds better than shorter plants, and grain yield increases quadratically with increasing plant height (Fageria, Castro \& Baligar, 2004) up to a point. Taller plants run a risk of lodging (Kato et al., 2019), and a small increase in grain yield has been related to reduced plant height (Evans, Visperas \& Vergara, 1984). Tiller number is crucial under biotic and abiotic stresses due to compensation processes. High tillering capacity is associated with the maximum use of space and resources; thus, this trait significantly affects 
323 total grain yield. Mainly, genotypes with a higher number of effective tillers per plant produce

324 higher rice grain yields (Dutta, Dutta \& Borua, 2013).

325 Yield potential of long duration rice genotypes under non-stress conditions

326 Yield and yield-related traits are a result of interactive physiological and biochemical processes

327

328

329

330

331

332

333

334

335

336

337

338

339

340

341

342

343

344

345

346

347

348

349

350

351

352

during the crop cycle. Grain yield is determined by panicle number, spikelets per panicle, spikelet fertility, and individual grain weight (Fig. 5). Genotype IR65600 produced the fewest panicles and spikelets panicle ${ }^{-1}$ and had the lowest grain yield among all rice genotypes (Table S1). Overall genotypes, $73 \%$ of the panicles had filled grains, with genotype HHZ1 containing as high as $96 \%$ and genotype IR74371 as low as $18 \%$ filled grains. Spikelet fertility was significantly affected by the year; more filled grains were observed in the first year with an average of $75 \%$ of the grains filled as compared to the second year with an average of $72 \%$ filled grains. Average panicle length, number of spikelet panicle ${ }^{-1}$, number of grain plant ${ }^{-1}$, and grain weight panicle ${ }^{-1}$ were $23.6 \mathrm{~cm}, 12.0$ no/panicle, 126.3 no/plant, and $2.12 \mathrm{~g}$, respectively (Table 1).

Panicles per plant and the number of spikelet numbers on each panicle play an essential role in increasing or decreasing the total grain yield. Genotype IR65600 produced the fewest spikelets panicle ${ }^{-1}$ and had the lowest grain yield among all the rice genotypes. On average, groups 1 and 2 had significantly greater grain weight, spikelet fertility, grain number, grain yield, and harvest index than group 4 (Fig. 5C-G). Significant differences were recorded for average grain yield across groups $(p<0.05)$, and group 1 and 2 genotypes were the highest yieldings (86.4 and $78.4 \mathrm{~g} \mathrm{plant}^{-1}$, respectively). In contrast, group 4 recorded the lowest yields (39.6 g plant $\left.^{-1}\right)$. The mean of group 1 and group 2 genotypes recorded the highest harvest index $(0.34)$, and the group 4 genotypes recorded the lowest $\mathrm{HI}(0.14)$. The bottom $10 \%$ of the $\mathrm{HI}$ genotypes were mostly long-duration genotypes which produced an average of 164.5 spikelets per panicle, which is $57.4 \%$ greater than the top $10 \%$ of high $\mathrm{HI}$ genotypes. Although spikelet number per panicle is correlated with yield, numerous spikelets per panicle might have to fight for nonstructural carbohydrates or concurrent photo assimilation during grain filling (Peng et al., 2008; Won et al., 2020). This becomes a bottleneck in high-yielding genotypes (Kikuchi et al., 2017; Fabre et al., 2020). An alternative route to overcome this shortfall would be short-duration plants with a better sink capacity (White et al., 2016). 
353

354

355

356

357

358

359

360

361

362

363

364

365

366

367

368

369

370

371

372

373

374

375

376

377

378

379

380

381

382

383

384

The degree of correlation among the traits is crucial, especially for a complex trait such as yield (Guan et al., 2010; Akinwale et al., 2011). Under non-stress conditions, yield component traits ( $G W, S F, G N$, and $G Y)$ are correlated $(r=0.45$ to $0.79, p<0.001)$ to harvest index, implying that selection for any of these could significantly improve yield. However, days to heading (anthesis) was negative correlated with GW $(r=-0.44, p<0.001)$, SF $(r=-0.52$, $p<0.001), G N(r=-0.47, p<0.001)$, GY $(r=-0.50, p<0.001)$ and $\mathrm{HI}(0=-0.79, p<0.001)$. While late-flowering or maturing genotypes could have a large grain filling window, resulting in higher grain yields by pushing extra photo-assimilates to the sink (grain) under optimum conditions.

Mississippi growing conditions do not appear to be optimum due to large variation in day-length compared to tropical regions (Philippines, India, Africa, and other tropical and subtropical regions), and late flowering/maturing genotypes are exposed to late-season cold weather during grain filling, which also induces yield losses.

Variability assessment based on physiological, growth, and yield responses index

Rex is a genotype (variety) popular in Mississippi because of adaptability and grain traits (https://www.mafes.msstate.edu/publications/information-bulletins/ib0548.pdf). Thus, the individual response index was calculated for all measured traits compared to the control genotype "Rex" (see Materials and methods). Correlations between agro-morphological, physiological, and yield-related traits with additive response indices are shown in Fig. 6, with the coefficient of determination $\left(R^{2}\right)$ values, which give the percentage of total differences or additive response index described by each independent variable. An overall high linear positive correlation was observed between the yield-related traits $\left(R^{2}=0.59\right)$ and the additive response index (ARI). In contrast, weak correlations were observed between ARI and growth and developmental traits $\left(R^{2}=0.21\right)$ and physiological traits $\left(R^{2}=0.28\right)$ for the selected rice genotypes (Fig. 6). A similar response index has been used as selection criteria for phenotyping cereals, legumes, and horticulture crops for abiotic stress tolerance, such as cold tolerance (Wijewardana et al., 2015), low or high-temperature tolerance (Jumaa et al., 2020; Reddy et al., 2021), drought tolerance (Lone et al., 2019; Singh et al., 2018), and salt tolerance (Kakar et al., 2019). The ARI values of all the genotypes and their standard deviations were further used to classify rice genotypes into four response groups, including low (and undesirable; $16.2 \%$ of the genotypes), moderately low (25.7\%), moderately high (32.4\%), and high (highly desirable;

$25.7 \%$ ) total response indices (Table 2 ).

Promising high yielding rice genotypes

Peer) reviewing PDF | (2021:03:58885:1:0:REVIEW 2 Jun 2021) 
385 Rice genotypes with a combination of smaller plant size and shorter crop duration compromise 386 harvest index under optimum conditions (Butler et al., 2005). However, combining the same 387 traits might positively impact stress conditions (Blum, 2011). Therefore, the proposed genotypes 388 (Table 3) with early flowering and better physiology (high Pn, Gs, and iWUE) have the 389 advantage of overcoming adverse climatic variabilities by enabling the genotype to utilize 390 resources more efficiently during critical growth stages. Under non-stress, 12DS-25 and 391 IR07F287 had the highest grain yield, which was more than twice the genotype Rex's yield.

392 Three genotypes, namely IR08A172, IR08N136, and CT18247 out yielded Rex with better Pn, 393 WUE, DH, SHW, GY, and HI. Most of the selected genotypes were characterized by a short 394 growing cycle. Genotypes IR07K142 and IR07F287 had a shorter duration to flowering, 395 accumulated high above-ground biomass and harvest index as compared to Rex and Apo. 396 Three genotypes (12DS-25, IR07F287, and IR07K142) surpassed Apo's grain yield in the 397 experiment. Genotypes 12DS-25, IR07F287, IR07K142 and Apo, had the highest grain yields, 398 but their Pn values were lower by $22.4 \%, 21 \%, 18.8 \%$, and $22 \%$ compared with the highest $\mathrm{Pn}$ 399 genotype, IR08N136 (Table 3). These results indicated that higher photosynthetic efficiency cannot always increase grain yield because $\mathrm{Pn}$ is a complex process controlled by many genes (Gu et al., 2014). Among the best performers, IR08A172, IR07K142, and IR07F287 were ranked high in physiological and yield response indices (Table 3). The yield difference between the top-yielding short-duration genotype, IR07F287, and Apo was $76 \mathrm{~g} \mathrm{plant}^{-1}$. We identified rice 404 genotypes with days to heading similar to Rex to explore the physiological attributes associated 405 with high yield in the short-duration genotypes. However, IR07K142 and IR07F287 were the 406 earliest heading/maturing genotypes with greater yield. We speculate that short-duration genotypes with higher photo assimilation during the grain-filling stage may increase yield and 408 quality.

\section{Conclusions}

410 Overall, the studied rice genotypes exhibited substantial variability for the measured growth and 411 developmental, physiological, and yield-related traits. PCA analysis indicated that yield-related and physiological characteristics are more important for assessing the overall phenotypic variability and characterization of genotypes, followed by growth and developmental traits. Fiftyeight percent of the genotypes were classified with moderately high and high additive index. It appears that low sink capacity during grain-filling becomes a primary cause of the antagonistic relation between long-duration and harvest index. The higher harvest index in genotypes 
418 potential of the identified donors for developing new rice for Mid-south USA growing 419 environments. . The exploited variability and diversity could be useful for trait-based breeding.

420 We recommend understanding short-duration genotype responses to future climatic conditions 421 such as elevated $\mathrm{CO}_{2}$, warmer temperature, and drought to solve the source and sink 422 relationship puzzle.

\section{Acknowledgments}

424 This work was partially supported by the US Agency for International Development (USAID) 425 through CIMMYT, the Mississippi Rice Promotion Board, and National Institute for Food and 426 Agriculture, NIFA 2019-34263-30552 and MIS 043050. We thank the International Rice 427 Research Institute (IRRI) for providing rice genotypes for the project. We also thank the 428 Environmental Plant Physiology Lab staff and students for their technical help and data 429 collection.

\section{References}

431

432

433

434

435

436

437

438

439

440

441

442

443

444

445

446

447

Abdelkhalik AF, Shishido R, Nomura K, Ikehashi H. 2005. QTL-based analysis of leaf senescence in an indica/japonica hybrid in rice (Oryza sativa L.). Theoretical and Applied Genetics 110:1226-1235 DOI: 10.1007/s00122-005-1955-2.

Akinwale MG, Gregorio G, Nwilene F, Akinyele BO, Ogunbayo SA, Odiyi AC. 2011. Heritability and correlation coefficient analysis for yield and its components in rice (Oryza sativa L.). African Journal of Plant Science 5:207-212 DOI: 10.5897/AJPS.9000137.

Amanullah, Inamullah. 2016. Dry matter partitioning and harvest index differ in rice genotypes with variable rates of phosphorus and zinc nutrition. Rice Science 23:78-87 DOI: 10.1016/j.rsci.2015.09.006.

Anyia A. 2004. Water-use efficiency, leaf area and leaf gas exchange of cowpeas under midseason drought. European Journal of Agronomy 20:327-339 DOI: 10.1016/S11610301(03)00038-8.

Blum A. 2011. Plant Breeding for Water-Limited Environments. New York: Springer-Verlag. DOI: 10.1007/978-1-4419-7491-4.

Butler JD, Byrne PF, Mohammadi V, Chapman PL, Haley SD. 2005. Agronomic performance of Rht alleles in a spring wheat population across a range of moisture levels. Crop Science 45:939-947 DOI: 10.2135/cropsci2004.0323. 
448 Chapple C, Vogt T, Ellis BE, Somerville CR. 1992. An Arabidopsis mutant defective in the

449

450

451

452

453

454

455

456

457

458

459

460

461

462

463

464

465

466

467

468

469

470

471

472

473

474

475

476

477

478

479

480

general phenylpropanoid pathway. The Plant Cell 4:1413-1424. DOI:

10.1105/tpc.4.11.1413.

Craufurd PQ, Wheeler TR, Ellis RH, Summerfield RJ, Williams JH. 1999. Effect of temperature and water deficit on water-use efficiency, carbon isotope discrimination, and specific leaf area in peanut. Crop Science 39:136-142 DOI:10.2135/cropsci1999.0011183X003900010022x.

Du X, Jin X, Yang X, Yang X, Xiang X, Zhou Y. 2015. Spatial-temporal pattern changes of main agriculture natural disasters in China during 1990-2011. Journal of Geographical Sciences 25:387-398 DOI: 10.1007/s11442-015-1175-x.

Dutta P, Dutta PN, Borua PK. 2013. Morphological Traits as Selection Indices in Rice: A Statistical View.

Evans LT, Visperas RM, Vergara BS. 1984. Morphological and physiological changes among rice varieties used in the Philippines over the last seventy years. Field Crops Research 8:105-124 DOI: 10.1016/0378-4290(84)90055-8.

Fabre D, Dingkuhn M, Yin X, Clément-Vidal A, Roques S, Soutiras A, Luquet D. 2020.

Genotypic variation in source and sink traits affects the response of photosynthesis and growth to elevated atmospheric $\mathrm{CO}_{2}$. Plant, Cell \& Environment 43:579-593 DOI: 10.1111/pce.13693.

Fageria NK, Castro EM, Baligar VC. 2004. Response of upland rice genotypes to soil acidity. In: Wilson MJ, He Z, Yang X eds. The red soils of china. Dordrecht: Springer Netherlands, 219-237 DOI: 10.1007/978-1-4020-2138-1_14.

Foley JA, Ramankutty N, Brauman KA, Cassidy ES, Gerber JS, Johnston M, Mueller ND, O'Connell C, Ray DK, West PC, Balzer C, Bennett EM, Carpenter SR, Hill J, Monfreda C, Polasky S, Rockström J, Sheehan J, Siebert S, Tilman D, Zaks DPM. 2011. Solutions for a cultivated planet. Nature 478:337-342 DOI: 10.1038/nature10452.

Gu J, Yin X, Stomph T-J, Struik PC. 2014. Can exploiting natural genetic variation in leaf photosynthesis contribute to increasing rice productivity? A simulation analysis. Plant, Cell \& Environment 37:22-34 DOI: 10.1111/pce.12173.

Guan YS, Serraj R, Liu SH, Xu JL, Ali J, Wang WS, Venus E, Zhu LH, Li ZK. 2010. Simultaneously improving yield under drought stress and non-stress conditions: a case study of rice (Oryza sativa L.). Journal of Experimental Botany 61:4145-4156 DOI: 10.1093/jxb/erq212.

Peer] reviewing PDF | (2021:03:58885:1:0:REVIEW 2 Jun 2021) 
481 Haritha G, Vishnukiran T, Yugandhar P, Sarla N, Subrahmanyam D. 2017. Introgressions from

482

483

484

485

486

487

488

489

490

491

492

493

494

495

496

497

498

499

500

501

502

503

504

505

506

507

508

509

510

511

512

513 Oryza rufipogon increase photosynthetic efficiency of KMR3 rice lines. Rice Science 24:85-96 DOI: 10.1016/j.rsci.2016.07.006.

Huang R, Jiang L, Zheng J, Wang T, Wang H, Huang Y, Hong Z. 2013. Genetic bases of rice grain shape: so many genes, so little known. Trends in Plant Science 18:218-226 DOI: 10.1016/j.tplants.2012.11.001.

Jumaa SH, Kakar N, Redoña ED, Lone AA, Chastain D, Gao W, Warburton ML, Reddy KR. 2020. Assessing the early-season vigor of a diverse rice population by using morphophysiological traits. SABRAO Journal of Breeding \& Genetics 52:248-270.

Kakar N, Jumaa SH, Redoña ED, Warburton ML, Reddy KR. 2019. Evaluating rice for salinity using pot-culture provides a systematic tolerance assessment at the seedling stage. Rice 12:57 DOI: 10.1186/s12284-019-0317-7.

Kato Y, Collard BCY, Septiningsih EM, Ismail AM. 2019. Increasing flooding tolerance in rice: combining tolerance of submergence and of stagnant flooding. Annals of Botany 124:1199-1209 DOI: 10.1093/aob/mcz118.

Kikuchi S, Bheemanahalli R, Jagadish KSV, Kumagai E, Masuya Y, Kuroda E, Raghavan C, Dingkuhn M, Abe A, Shimono H. 2017. Genome-wide association mapping for phenotypic plasticity in rice: Genome-wide association mapping and rice plasticity. Plant, Cell \& Environment 40:1565-1575 DOI: 10.1111/pce.12955.

Kondamudi R, Swamy K, Rao YV, Kiran TV, Suman K, Rao DS, Rao PR, Subrahmanyam D, Sarla N, Kumari BR. 2016. Gas exchange, carbon balance and stomatal traits in wild and cultivated rice (Oryza sativa L.) genotypes. Acta Physiologiae Plantarum 38:160 DOI: $10.1007 / \mathrm{s} 11738-016-2173-z$

Kropff MJ, Van LHH, Matthews RB. 1994. ORYZA1: an ecophysiological model for irrigated rice production. Los Baños, Philippines: International Rice Research Institute.

Kumar A, Dixit S, Ram T, Yadaw RB, Mishra KK, Mandal NP. 2014. Breeding high-yielding drought-tolerant rice: genetic variations and conventional and molecular approaches. Journal of Experimental Botany 65:6265-6278 DOI: 10.1093/jxb/eru363.

Lesk C, Rowhani P, Ramankutty N. 2016. Influence of extreme weather disasters on global crop production. Nature 529:84-87 DOI: 10.1038/nature16467.

Lone AA, Jumaa SH, Wijewardana C, Taduri S, Redona ED, Reddy KR. 2019. Drought stress tolerance screening of elite american breeding rice genotypes using low-cost prefabricated mini-hoop modules. Agronomy 9:199 DOI: 10.3390/agronomy9040199. 
514 Li R, Li M, Ashraf U, Liu S, Zhang J. 2019. Exploring the relationships between yield and yield515 related traits for rice varieties released in China from 1978 to 2017. Frontiers in Plant $516 \quad$ Science 10 DOI: 10.3389/fpls.2019.00543.

517 Li G, Zhang J, Yang C, Song Y, Zheng C, Wang S, Liu Z, Ding Y. 2014. Optimal yield-related 518 attributes of irrigated rice for high yield potential based on path analysis and stability 519 analysis. The Crop Journal 2:235-243 DOI: 10.1016/j.cj.2014.03.006.

520 Lichtenthaler HK. 1987. Chlorophylls and carotenoids: Pigments of photosynthetic $521 \quad$ biomembranes. In: Methods in Enzymology. Elsevier, 350-382. DOI: 10.1016/0076522 6879(87)48036-1.

523 Long SP, Zhu X-G, Naidu SL, Ort DR. 2006. Can improvement in photosynthesis increase crop 524 yields? Plant, Cell \& Environment 29:315-330 DOI: 10.1111/j.1365-3040.2005.01493.x.

526

527

528

529

McKenzie KS, Sha X, Moldenhauer KAK, Linscombe SD, Lyman NB, Nalley LL. 2015. Rice. In:

530

531

532

Lu Z, Radin JW, Turcotte EL, Percy R, Zeiger E. 1994. High yields in advanced lines of Pima cotton are associated with higher stomatal conductance, reduced leaf area and lower leaf temperature. Physiologia Plantarum 92:266-272. DOI: 10.1111/j.1399-

Mehetre SS, Mahajan CR, Patil PA, Lad SK, Dhumal PM (College of A. 1994. Variability, heritability, correlation, path analysis, and genetic divergence studies in upland rice. International Rice Research Notes (Philippines). Smith S, Diers B, Specht J, Carver B eds. CSSA Special Publications. Madison, WI, USA: American Society of Agronomy and Soil Science Society of America, 267-292. DOI: 10.2135/cssaspecpub33.c10.

Mohammadi R, Haghparast R, Amri A, Ceccarelli S. 2010. Yield stability of rainfed durum wheat and GGE biplot analysis of multi-environment trials. Crop and Pasture Science 61:92 DOI: $10.1071 /$ CP09151.

Peng S, Khush GS, Virk P, Tang Q, Zou Y. 2008. Progress in ideotype breeding to increase rice yield potential. Field Crops Research 108:32-38 DOI: 10.1016/j.fcr.2008.04.001.

Placido DF, Campbell MT, Folsom JJ, Cui X, Kruger GR, Baenziger PS, Walia H. 2013. Introgression of novel traits from a wild wheat relative improves drought adaptation in wheat. Plant Physiology 161:1806-1819 DOI: 10.1104/pp.113.214262.

Prasad PVV, Djanaguiraman M. 2011. High night temperature decreases leaf photosynthesis and pollen function in grain sorghum. Functional Plant Biology 38:993 DOI: 10.1071/FP11035. 
547 Ray DK, Ramankutty N, Mueller ND, West PC, Foley JA. 2012. Recent patterns of crop yield

548

549

550

551

552

553

554

555

556

557

558

559

560

561

562

563

564

565

566

567

568

569

570

571

572

573

574

575

576

577

578 growth and stagnation. Nature Communications 3:1293 DOI: 10.1038/ncomms2296.

Reddy KR, Seghal A, Jumaa S, Bheemanahalli R, Kakar N, Redoña ED, Wijewardana C, Alsajri FA, Chastain D, Gao W, Taduri S, Lone AA. 2021. Morpho-physiological characterization of diverse rice genotypes for seedling stage high- and low-temperature tolerance. Agronomy 11:112 DOI: 10.3390/agronomy11010112.

Sakamoto T, Matsuoka M. 2008. Identifying and exploiting grain yield genes in rice. Current Opinion in Plant Biology 11:209-214 DOI: 10.1016/j.pbi.2008.01.009.

Samonte SO, Wilson LT, McClung AM. 1998. Path analyses of yield and yield-related traits of fifteen diverse rice genotypes. Crop Science 38:1130-1136 DOI: 10.2135/cropsci1998.0011183X003800050004x.

Sheshshayee M, Bindumadhava H, Rachaputi N, Prasad T, Udayakumar M, Wright G, Nigam S. 2006. Leaf chlorophyll concentration relates to transpiration efficiency in peanut. Annals of Applied Biology 148:7-15. DOI: 10.1111/j.1744-7348.2005.00033.x.

Shin D, Lee S, Kim T-H, Lee J-H, Park J, Lee J, Lee JY, Cho L-H, Choi JY, Lee W, Park J-H, Lee D-W, Ito H, Kim DH, Tanaka A, Cho J-H, Song Y-C, Hwang D, Purugganan MD, Jeon J-S, An G, Nam HG. 2020. Natural variations at the Stay-Green gene promoter control lifespan and yield in rice cultivars. Nature Communications 11:2819 DOI: 10.1038/s41467-020-16573-2.

Singh K, Wijewardana C, Gajanayake B, Lokhande S, Wallace T, Jones D, Reddy KR. 2018. Genotypic variability among cotton cultivars for heat and drought tolerance using reproductive and physiological traits. Euphytica 214:57 DOI: 10.1007/s10681-018-21351.

Syed S, Rasmus H, Matthew M. 2017. Response of chlorophyll, carotenoid and spad-502 measurement to salinity and nutrient stress in wheat (Triticum aestivum L.). Agronomy 7:61 DOI: 10.3390/agronomy7030061.

Vikram P, Swamy BPM, Dixit S, Trinidad J, Sta Cruz MT, Maturan PC, Amante M, Kumar A. 2016. Linkages and Interactions Analysis of Major Effect Drought Grain Yield QTLs in Rice. PloS One 11:e0151532 DOI: 10.1371/journal.pone.0151532.

White AC, Rogers A, Rees M, Osborne CP. 2016. How can we make plants grow faster? A source-sink perspective on growth rate. Journal of Experimental Botany 67:31-45 DOI: 10.1093/jxb/erv447. 
579 Won PLP, Liu H, Banayo NPM, Nie L, Peng S, Islam MR, Sta. Cruz P, Collard BCY, Kato Y. 580 2020. Identification and characterization of high-yielding, short-duration rice genotypes 581 for tropical Asia. Crop Science 60:2241-2250 DOI: 10.1002/csc2.20183.

582 Xing Y, Zhang Q. 2010. Genetic and molecular bases of rice yield. Annual Review of Plant 583 Biology 61:421-442 DOI: 10.1146/annurev-arplant-042809-112209.

584 Yoshida S, Satake T, Mackill DS. 1981. High-temperature stress in rice [study conducted at 585 IRRI, Philippines]. IRRI Research Paper Series (Philippines).

586 Zafar SA, Hameed A, Nawaz MA, Ma W, Noor MA, Hussain M, Mehboob-ur-Rahman. 2018.

587 Mechanisms and molecular approaches for heat tolerance in rice (Oryza sativa L.) under

588 climate change scenario. Journal of Integrative Agriculture 17:726-738. DOI:

589 10.1016/S2095-3119(17)61718-0.

590 Zhao M, Ding Z, Lafitte R, Sacks E, Dimayuga G, Holt D. 2010. Photosynthetic characteristics in 591 Oryza species. Photosynthetica 48:234-240 DOI: 10.1007/s11099-010-0029-0.

592 Zhu X-G, Long SP, Ort DR. 2008. What is the maximum efficiency with which photosynthesis 593 can convert solar energy into biomass? Current Opinion in Biotechnology 19:153-159 DOI: 10.1016/j.copbio.2008.02.004. 


\section{Figure 1}

The principal component analysis (PCA) of the morpho-physiological and yield-related traits with the first two principal components (PC1 and PC2) in non-stress [A].

Trait labels are colored differently according to trait category (physiological traits in Orange, morphological traits in Black, and yield-related traits in Purple) in Table 1; acronyms are given in Table 1. Contribution (Cont) of the variables (\%) and correlations (Cor) between variables and factors to the principal components [B]. Classification of 74 rice genotypes based on the factor scores of first (PC1) and second (PC2) principal components. G1 to G4 represents rice genotypes grouping [C]. 


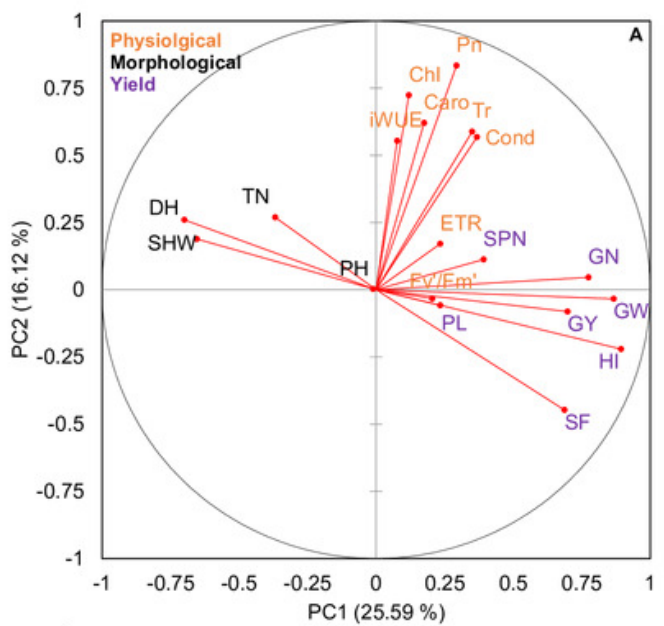

\begin{tabular}{|c|c|c|c|c|c|c|}
\hline B & \multicolumn{2}{|c|}{$\mathrm{PC} 1$} & \multicolumn{2}{|c|}{$\mathrm{PC} 2$} & \multicolumn{2}{|c|}{ PC3 } \\
\hline Eigenvalue & \multicolumn{2}{|c|}{4.9} & \multicolumn{2}{|c|}{3.1} & \multicolumn{2}{|c|}{2.6} \\
\hline Variability (\%) & \multicolumn{2}{|c|}{25.6} & \multicolumn{2}{|c|}{16.1} & \multicolumn{2}{|c|}{13.5} \\
\hline \multirow[t]{2}{*}{ Cumulative \% } & \multicolumn{2}{|c|}{25.6} & \multicolumn{2}{|c|}{41.7} & \multicolumn{2}{|c|}{55.2} \\
\hline & Cont & Cor & Cont & Cor & Cont & Cor \\
\hline $\mathrm{Pn}$ & 1.76 & 0.29 & 22.73 & 0.83 & 2.08 & -0.23 \\
\hline Cond & 2.78 & 0.37 & 10.54 & 0.57 & 8.95 & -0.48 \\
\hline $\mathrm{Tr}$ & 2.52 & 0.35 & 11.28 & 0.59 & 10.01 & -0.51 \\
\hline WUE & 0.12 & 0.08 & 10.01 & 0.55 & 2.98 & 0.28 \\
\hline $\mathrm{Fv}^{\prime} / \mathrm{Fm}$ & 0.86 & 0.20 & 0.04 & -0.03 & 0.39 & 0.10 \\
\hline ETR & 1.13 & 0.23 & 0.96 & 0.17 & 0.09 & 0.05 \\
\hline Chl & 0.29 & 0.12 & 17.12 & 0.72 & 3.44 & 0.30 \\
\hline Caro & 0.63 & 0.17 & 12.59 & 0.62 & 2.70 & 0.26 \\
\hline $\mathrm{DH}$ & 10.07 & -0.70 & 2.21 & 0.26 & 0.07 & 0.04 \\
\hline TN & 2.78 & -0.37 & 2.38 & 0.27 & 14.39 & 0.61 \\
\hline $\mathrm{PH}$ & 0.00 & -0.01 & 0.00 & 0.00 & 14.47 & 0.61 \\
\hline SHW & 8.80 & -0.65 & 1.17 & 0.19 & 15.32 & 0.63 \\
\hline PL & 1.12 & 0.23 & 0.11 & -0.06 & 8.65 & 0.47 \\
\hline SPN & 3.16 & 0.39 & 0.42 & 0.11 & 3.44 & 0.30 \\
\hline GW & 15.45 & 0.87 & 0.04 & -0.03 & 1.02 & 0.16 \\
\hline SF & 9.71 & 0.69 & 6.54 & -0.45 & 0.61 & 0.13 \\
\hline $\mathrm{GN}$ & 12.34 & 0.77 & 0.07 & 0.05 & 3.36 & 0.29 \\
\hline GY & 10.04 & 0.70 & 0.21 & -0.08 & 7.94 & 0.45 \\
\hline $\mathrm{HI}$ & 16.43 & 0.89 & 1.59 & -0.22 & 0.07 & -0.04 \\
\hline
\end{tabular}

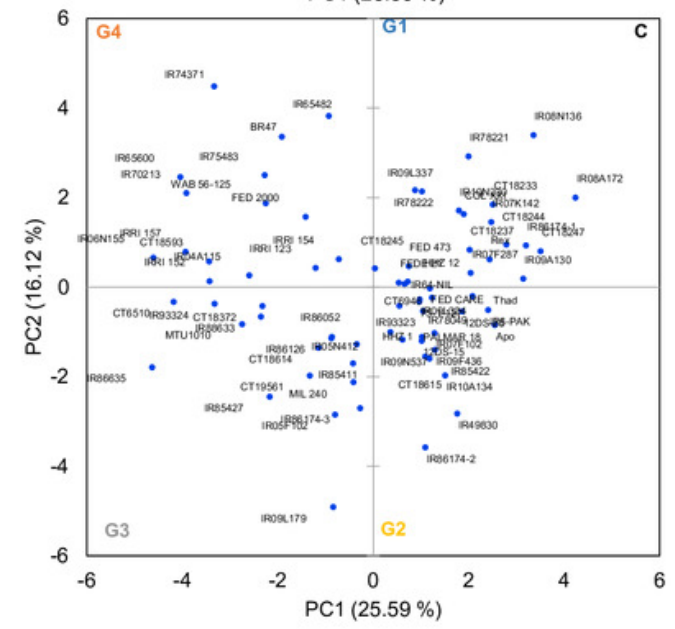




\section{Figure 2}

Pearson's correlation coefficients among 74 rice genotypes in non-stress conditions.

Correlations values with \pm indicate a strong between two traits. *,**,*** - significance at $<0.05 ;<0.01 ;<0.001$, respectively. Physiological traits: Net photosynthesis (Pn), Stomata conductance (Cond), Transpiration rate (Tr), Water use efficiency (iWUE), chlorophyll fluorescence ( $\left.\mathrm{Fv}^{\prime} / \mathrm{Fm}^{\prime}\right)$, Electron transport rate (ETR), Total chlorophyll (Chl) and Carotenes (Caro); Morphological traits: days to heading (DH, d), tiller number (TN, per plant), plant height ( $\mathrm{PHT}, \mathrm{cm}$ ) and shoot dry weight (SHW, g per plant); yield-related traits: panicle length (PN, cm), spikelet number per panicle (SPN, no per panicle), grain weight per panicle (GW, $\mathrm{g}$ per panicle), spikelet fertility (SF, \%), grain number per plant (GN, per plant), grain yield (GY, $\mathrm{g}$ per plant) and harvest index (HI, plant basis) traits values among 74 rice genotypes in nonstress conditions. 


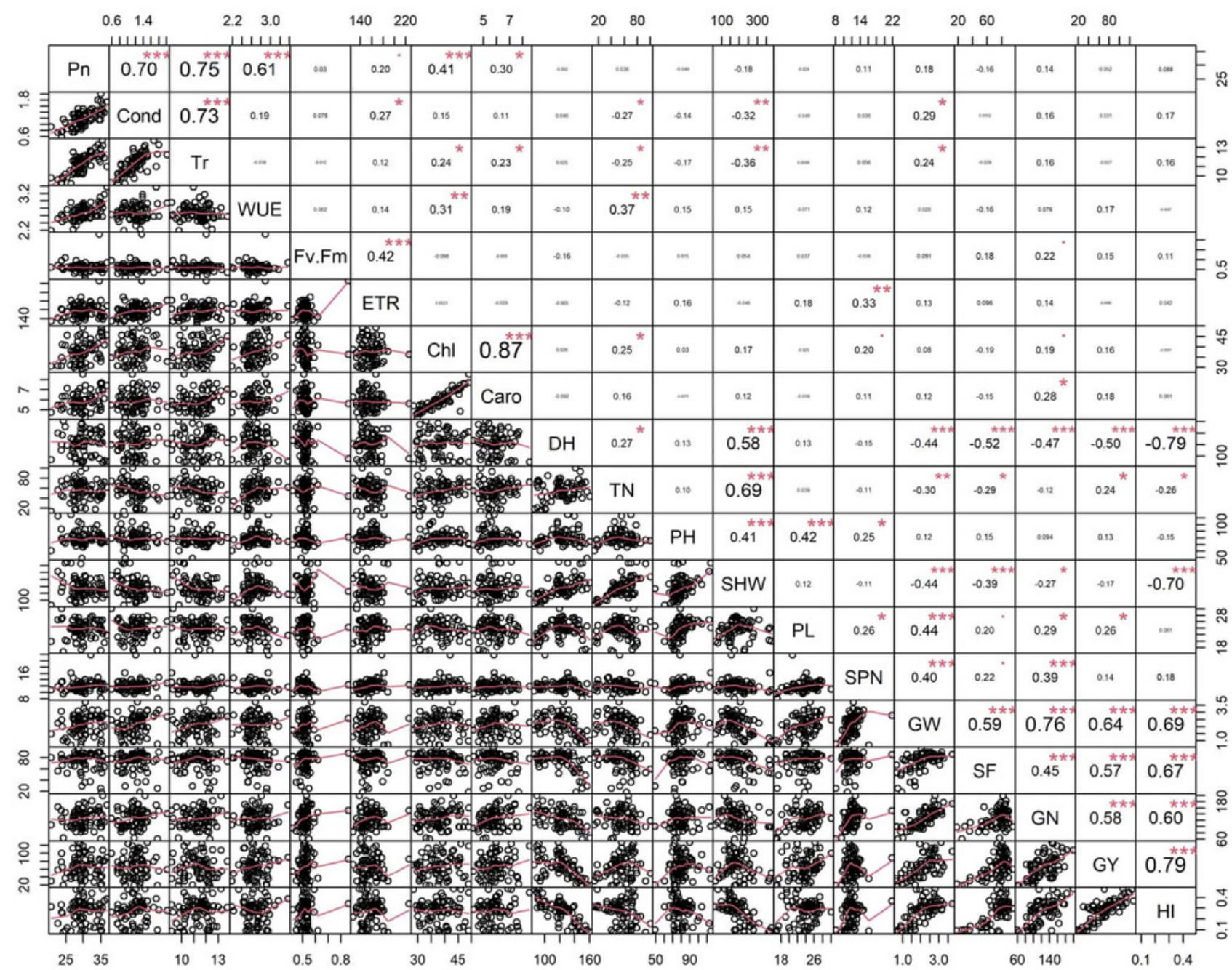




\section{Figure 3}

Boxplots showing differences in physiological traits.

Boxplot showing difference in physiological traits such as [A] net photosynthesis (Pn, $\mu \mathrm{mol}$ $\mathrm{m}^{-2} \mathrm{~s}^{-1}$ ), [B] stomatal conductance (Cond, $\mathrm{mol} \mathrm{m}^{-2} \mathrm{~s}^{-1}$ ), [C] leaf transpiration rate $\left(\mathrm{Tr}, \mathrm{mmol} \mathrm{H}_{2} \mathrm{O}\right.$ $\mathrm{m}^{-2} \mathrm{~s}^{-1}$ ), [D] water use efficiency (WUE, mmol $\mathrm{CO}_{2} \mathrm{~mol}^{-1} \mathrm{H}_{2} \mathrm{O}$ ), [E] chlorophyll fluorescence $\left(F^{\prime} / F m^{\prime}\right),[F]$ electron transport rate (ETR, $\left.\mu \mathrm{mol} \mathrm{m}^{-2} \mathrm{~s}^{-1}\right),[\mathrm{G}]$ Chlorophyll contents (Chl) and $[\mathrm{H}]$ carotenoids (Caro) values among four groups of rice under non-stress conditions. The four groups ( $G 1$ to $G 4$ ) represent rice genotype grouping based on the first and second principal components (see Fig. 1B). Different letters on the boxplot indicate a significant difference among the groups $(p<0.05)$. 

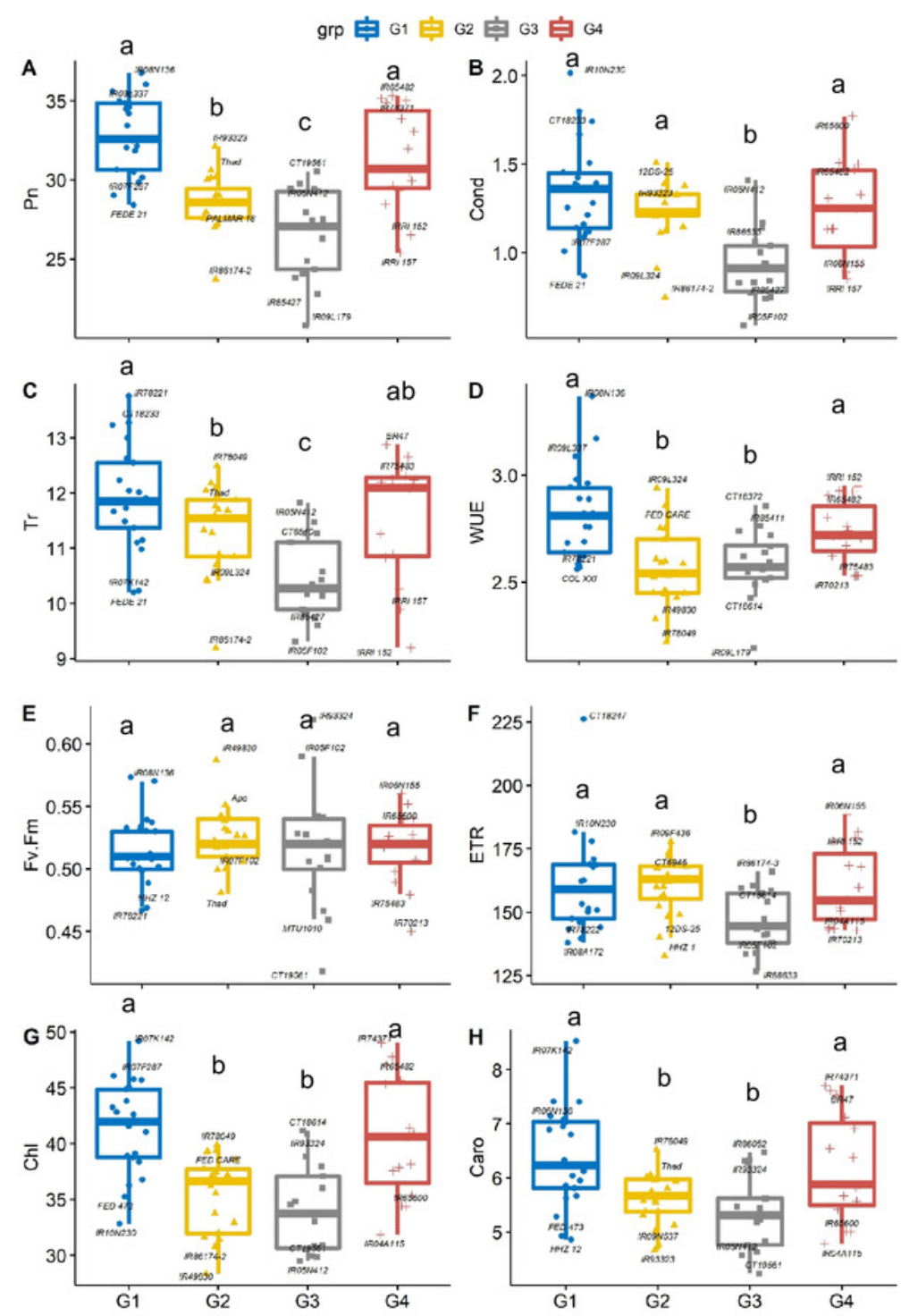


\section{Figure 4}

Boxplots showing the differences in $[A]$ days to heading $(\mathrm{DH}, \mathrm{d}),[\mathrm{B}]$ tiller number (TN, per plant), [C] plant height (PHT, cm), and [D] shoot dry weight (SHW, g per plant) traits values among four groups of rice genotypes under non-stress conditions.

The four groups (G1 to G4) represent rice genotype grouping based on the first and second principal components (see Fig. 1B). Different letters on the boxplot indicate a significant difference among the groups $(p<0.05)$. 


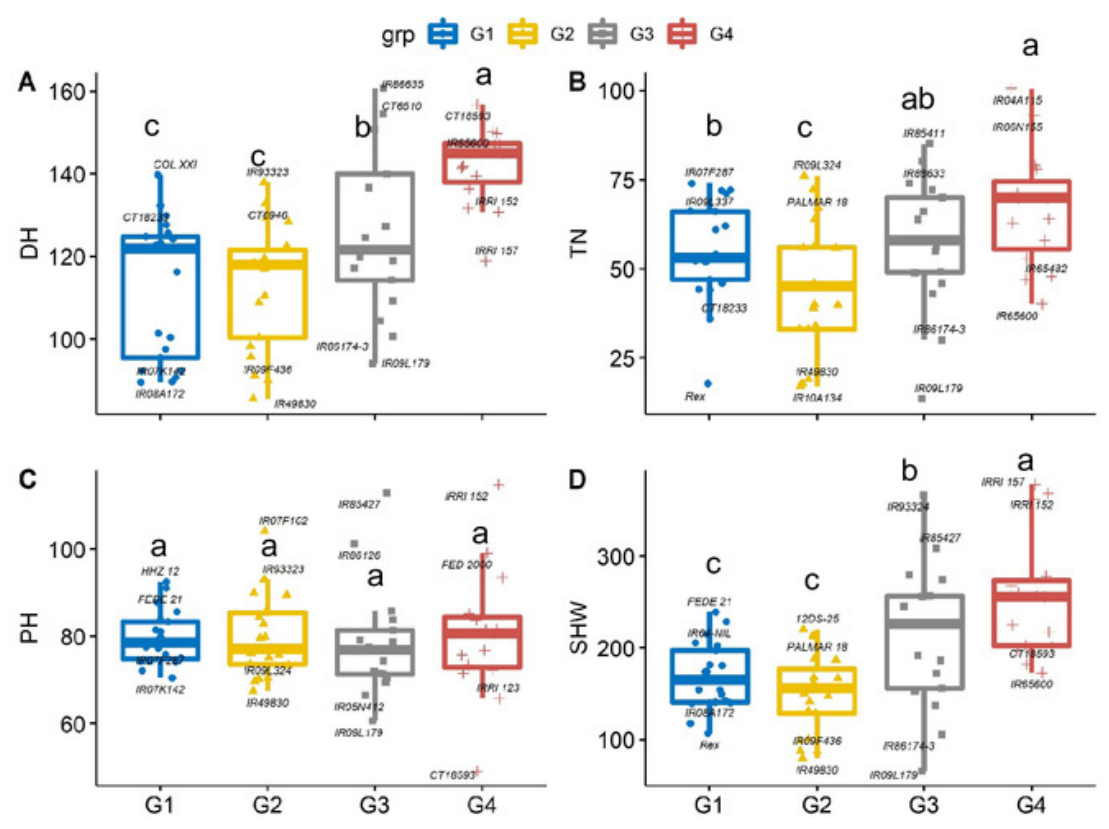




\section{Figure 5}

Boxplots showing the differences in yield and yield components traits

Phenotypic distribution of [A] panicle length ( $\mathrm{cm}$ ), [B] Spikelet number (SPN, no. panicle-1), [C] grain weight (GW, g panicle-1), [D] spikelet fertility (SF, \%), [E] grain number (GN, no.

plant $^{-1}$ ), [F] grain yield (GY, g plant ${ }^{-1}$ ) and [G] Harvest index (HI) among four groups of rice genotypes under non-stress conditions. The four groups (G1 to G4) represent rice genotype grouping based on the first and second principal components (see Fig. 1B). Different letters on the boxplot indicate a significant difference among the groups $(p<0.05)$. 

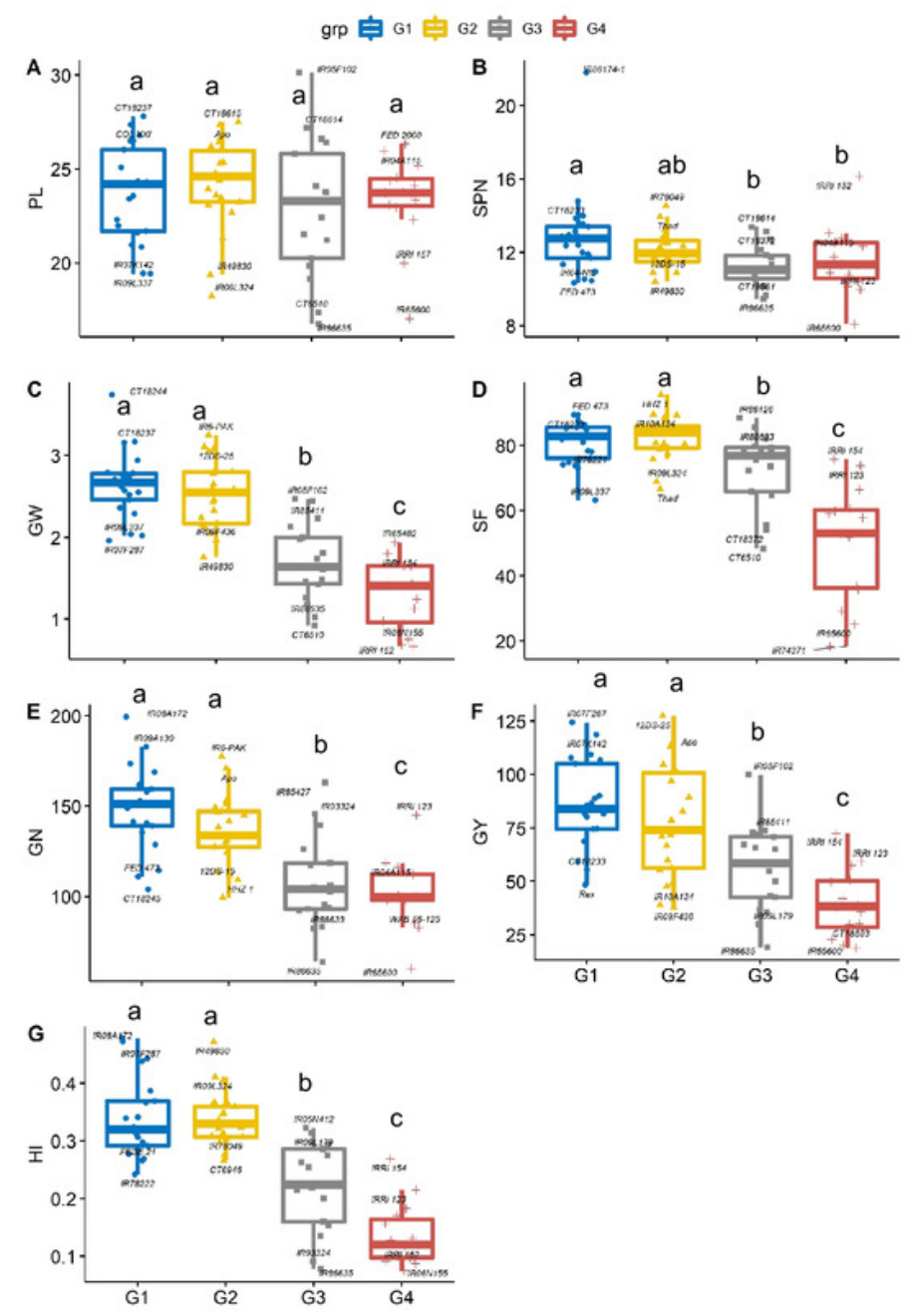
Figure 6

The relationship between total additive response index and shoot (square), physiological (triangle) and yield (open circle) individual response index of 74 rice genotypes. 


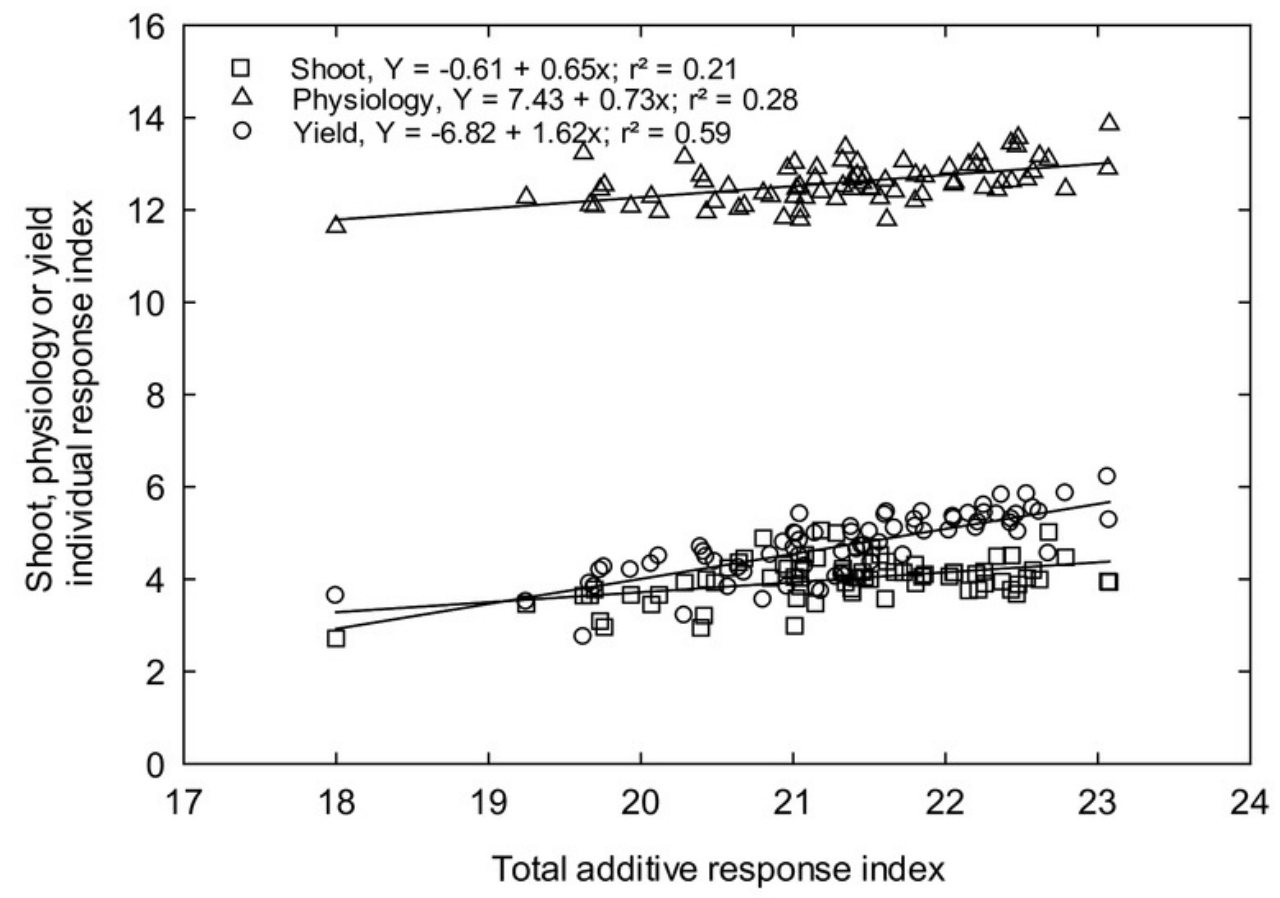




\section{Table $\mathbf{1}$ (on next page)}

Analysis of variance (ANOVA) across 74 rice genotypes for morpho-physiological and yield-related traits measured during vegetative and grain filling stages for two years.

Significance level: ${ }^{*} p<0.05,{ }^{* *} p<0.01,{ }^{* * *} p<0.001 ; N S$, non-significant. SD - standard deviation. 
Table 1 Analysis of variance (ANOVA) across 74 rice genotypes for morpho-physiological and yield-related traits measured during vegetative and grain filling stages for two years. Significance level: ${ }^{*} \mathrm{p}<0.05,{ }^{* *} \mathrm{p}<0.01,{ }^{* * *} \mathrm{p}<0.001$; NS, non-significant.

3 SD - standard deviation.

\begin{tabular}{|c|c|c|c|c|c|c|c|c|}
\hline \multirow{2}{*}{ Trait } & \multirow{2}{*}{ Trait Acronym/Unit } & \multicolumn{3}{|c|}{ Two-way ANOVA } & \multirow{2}{*}{ Minimum } & \multirow{2}{*}{ Maximum } & \multirow{2}{*}{ Mean } & \multirow{2}{*}{ SD } \\
\hline & & Cultivar (C) & Year (Y) & $\mathbf{C} \times \mathbf{Y}$ & & & & \\
\hline \multicolumn{9}{|l|}{ Physiological Traits } \\
\hline Net photosynthesis & $\mathrm{Pn}, \mu \mathrm{mol} \mathrm{m}{ }^{-2} \mathrm{~s}^{-1}$ & $* * *$ & NS & NS & 20.80 & 36.76 & 29.89 & 3.47 \\
\hline Stomata conductance & Cond, $\mathrm{mol} \mathrm{m} \mathrm{m}^{-2} \mathrm{~s}^{-1}$ & $* * *$ & NS & NS & 0.59 & 2.01 & 1.20 & 0.28 \\
\hline Transpiration rate & $\mathrm{Tr}, \mathrm{mmol} \mathrm{H}_{2} \mathrm{O} \mathrm{m}^{-2} \mathrm{~s}^{-1}$ & $* * *$ & NS & NS & 9.19 & 13.76 & 11.34 & 1.03 \\
\hline Water use efficiency & iWUE, $\mathrm{mmol} \mathrm{CO}_{2} \mathrm{~mol}^{-1} \mathrm{H}_{2} \mathrm{O}$ & $* * *$ & NS & NS & 2.19 & 3.37 & 2.68 & 0.20 \\
\hline Chlorophyll Fluorescence & $\mathrm{Fv}^{\prime} / \mathrm{Fm}^{\prime}$ & $* * *$ & NS & NS & 0.42 & 0.86 & 0.52 & 0.05 \\
\hline Electron transport rate & $\mathrm{ETR}, \mu \mathrm{mol} \mathrm{m} \mathrm{m}^{-2} \mathrm{~s}^{-1}$ & $* * *$ & NS & NS & 126.75 & 226.18 & 157.45 & 15.86 \\
\hline Total chlorophyll & $\mathrm{CHL}, \mu \mathrm{g} \mathrm{cm}^{-2}$ & $* * *$ & NS & NS & 28.35 & 49.19 & 37.84 & 5.22 \\
\hline Carotenes & Caro, $\mu \mathrm{g} \mathrm{cm}^{-2}$ & $* * *$ & NS & NS & 4.23 & 8.53 & 5.89 & 0.87 \\
\hline \multicolumn{9}{|l|}{ Morphological Traits } \\
\hline Days to $50 \%$ emergence & DE, days & $* * *$ & NS & NS & 8.0 & 12.0 & 10.16 & 0.92 \\
\hline Day to heading & $\mathrm{DH}$, days & $* * *$ & $* * *$ & $* *$ & 85.6 & 160.7 & 121.71 & 19.15 \\
\hline Plant height & $\mathrm{PH}, \mathrm{cm}_{\text {plant }}{ }^{-1}$ & $* * *$ & $* * *$ & $* * *$ & 13.5 & 100.5 & 54.63 & 18.03 \\
\hline Tiller number & $\mathrm{TN}$, no. plant $^{-1}$ & $* * *$ & $* * *$ & $* * *$ & 49.1 & 114.8 & 79.72 & 10.63 \\
\hline Shoot dry weight & SHW, g plant ${ }^{-1}$ & $* * *$ & NS & NS & 65.5 & 377.9 & 191.07 & 67.61 \\
\hline \multicolumn{9}{|l|}{ Yield-related Traits } \\
\hline Panicle length & $\mathrm{PL}, \mathrm{cm}$ & $* * *$ & NS & $* * *$ & 16.75 & 30.13 & 23.60 & 2.74 \\
\hline Spikelet number & SPN, no. panicle ${ }^{-1}$ & $* * *$ & NS & NS & 8.09 & 21.80 & 12.03 & 1.77 \\
\hline Grain weight & GW, g panicle ${ }^{-1}$ & $* * *$ & NS & NS & 0.67 & 3.74 & 2.12 & 0.69 \\
\hline Spikelet fertility & $\mathrm{SF}, \%$ & $* * *$ & $*$ & NS & 18.38 & 95.55 & 73.23 & 16.07 \\
\hline Grain number & GN, no. plant ${ }^{-1}$ & $* * *$ & NS & NS & 60.12 & 199.42 & 126.32 & 28.83 \\
\hline Grain yield & $G Y$, g plant ${ }^{-1}$ & $* *$ & NS & NS & 18.80 & 127.45 & 67.64 & 27.56 \\
\hline Harvest index & HI, plant basis & $* * *$ & NS & NS & 0.07 & 0.48 & 0.27 & 0.10 \\
\hline
\end{tabular}




\section{Table 2 (on next page)}

Classification of 74 tropical rice genotypes based on the cumulative response indices of morpho-physiological and yield-related traits measured during vegetative and grain filling and harvest stages in non-stress conditions. 
1 Table 2 Classification of 74 tropical rice genotypes based on the cumulative response indices 2 of morpho-physiological and yield-related traits measured during vegetative and grain filling 3 and harvest stages in non-stress conditions.

\begin{tabular}{|c|c|c|c|c|c|c|c|}
\hline \multicolumn{2}{|c|}{$\begin{array}{l}\text { High }(n=15) \\
(23.45-24.16)\end{array}$} & \multicolumn{2}{|c|}{$\begin{array}{c}\text { Moderately High }(\mathrm{n}=28) \\
(21.62-23.24)\end{array}$} & \multicolumn{2}{|c|}{$\begin{array}{c}\text { Moderately Low }(n=19) \\
(19.71-21.28)\end{array}$} & \multicolumn{2}{|c|}{$\begin{array}{c}\text { Low }(n=12) \\
(14.92-19.31)\end{array}$} \\
\hline $12 \mathrm{DS}-25$ & 24.16 & COL XXI & 23.24 & IR75483 & 21.28 & CT19561 & 19.31 \\
\hline IR08A172 & 24.12 & IR85411 & 23.24 & IR93323 & 21.25 & Rex & 19.00 \\
\hline CT18244 & 24.10 & IR86174-1 & 23.12 & MTU1010 & 21.12 & IR85422 & 18.91 \\
\hline IR07K142 & 24.10 & IR06N155 & 22.95 & IR70213 & 21.09 & Thad & 18.66 \\
\hline PALMAR 18 & 24.08 & CT18247 & 22.95 & IR65482 & 21.09 & CT18593 & 18.61 \\
\hline IR64-NIL & 23.96 & IR09N537 & 22.87 & IR86174-2 & 21.08 & IR86635 & 17.82 \\
\hline IR08N136 & 23.85 & IR78221 & 22.79 & $75-1-127$ & 21.05 & IR49830 & 17.81 \\
\hline IR07F287 & 23.67 & IR78222 & 22.75 & $12 \mathrm{DS}-15$ & 21.03 & IR86174-3 & 17.66 \\
\hline IR09A130 & 23.60 & IRRI 152 & 22.73 & IR6-PAK & 20.72 & IR10A134 & 17.64 \\
\hline IR04A115 & 23.56 & IR09L324 & 22.68 & СТ6946 & 20.56 & IR09F436 & 17.56 \\
\hline FEDE 21 & 23.54 & CT18615 & 22.62 & IR86052 & 20.49 & IR65600 & 17.53 \\
\hline Apo & 23.51 & IRRI 157 & 22.58 & IR74371 & 20.44 & IR09L179 & 14.92 \\
\hline FED 2000 & 23.50 & IRRI 154 & 22.57 & HHZ 1 & 20.33 & & \\
\hline IR05F102 & 23.50 & IR07F102 & 22.55 & IR05N412 & 20.14 & & \\
\hline \multirow[t]{14}{*}{ FED CARE } & 23.45 & HHZ 12 & 22.51 & IR78049 & 20.12 & & \\
\hline & & CT18237 & 22.50 & WAB 56-125 & 20.02 & & \\
\hline & & BR47 & 22.36 & СТ6510 & 19.99 & & \\
\hline & & IR09L337 & 22.29 & MIL 240 & 19.85 & & \\
\hline & & IR93324 & 22.11 & CT18372 & 19.71 & & \\
\hline & & IR88633 & 22.10 & & & & \\
\hline & & CT18245 & 21.88 & & & & \\
\hline & & FED 473 & 21.88 & & & & \\
\hline & & IR85427 & 21.88 & & & & \\
\hline & & IR86126 & 21.82 & & & & \\
\hline & & IRRI 123 & 21.75 & & & & \\
\hline & & CT18233 & 21.63 & & & & \\
\hline & & CT18614 & 21.63 & & & & \\
\hline & & IR10N230 & 21.62 & & & & \\
\hline
\end{tabular}

4 


\section{Table 3 (on next page)}

Recommended rice genotypes for use in high yielding environments.

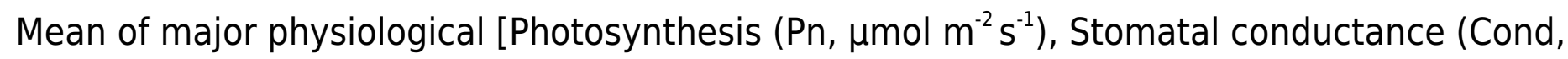
mol m $\mathrm{m}^{-2} \mathrm{~s}^{-1}$ ), intrinsic water use efficiency (iWUE, $\mu \mathrm{mol} \mathrm{m} \mathrm{m}^{-2} \mathrm{~s}^{-1} / \mathrm{mmol} \mathrm{H}_{2} \mathrm{O} \mathrm{m}^{-2} \mathrm{~s}^{-1}$ ), and total chlorophyll ( $\mathrm{Chl}, \mu \mathrm{g} \mathrm{cm}^{-2}$ )], morphological (days to heading ( $\mathrm{DH}$, days), plant height (PHT, $\mathrm{cm}$ ) and shoot dry weight (SHW, g per plant)], and yield-related [panicle length (PN, $\mathrm{cm}$ ), grain yield (GY, g per plant) and harvest index ( $\mathrm{HI}$, plant basis)] traits in non-stress conditions averaged across years are shown along with additive response indices (ARI) for selected genotypes. 


\begin{tabular}{llllllllllll}
\hline Genotype & Pn & Cond & iWUE & Chl & DH & PH & SHW & PL & GY & HI & CRI \\
\hline 12DS-25 & 28.52 & 1.51 & 2.61 & 39.26 & 118.4 & 90.1 & 220.01 & 26.2 & 127.45 & 0.36 & 24.16 \\
IR08A172 & 35.6 & 1.45 & 2.81 & 43.26 & 89.6 & 74.2 & 117.55 & 22.3 & 107.83 & 0.47 & 24.12 \\
IR07K142 & 29.86 & 1.12 & 2.89 & 49.19 & 89.7 & 70.5 & 149.45 & 19.45 & 118.72 & 0.44 & 24.10 \\
IR08N136 & 36.76 & 1.74 & 3.37 & 45.71 & 90.8 & 74.1 & 142.48 & 21.7 & 90.12 & 0.38 & 23.85 \\
IR07F287 & 29.04 & 1.01 & 2.64 & 46.08 & 92.3 & 72.1 & 139.37 & 21.98 & 124.41 & 0.47 & 23.67 \\
IR09A130 & 32.48 & 1.16 & 2.62 & 38.77 & 97.5 & 75.9 & 140.49 & 21.63 & 109.39 & 0.43 & 23.60 \\
Apo & 28.68 & 1.28 & 2.46 & 36.86 & 119.6 & 76.7 & 167.46 & 27.35 & 113.81 & 0.40 & 23.51 \\
IR86174-1 & 32.14 & 1.21 & 2.96 & 41.95 & 100.4 & 78.6 & 153.87 & 20.85 & 88.86 & 0.36 & 23.12 \\
CT18247 & 34.60 & 1.36 & 2.89 & 36.28 & 95.5 & 81.1 & 165.32 & 24.2 & 85.53 & 0.34 & 22.95 \\
\hline Rex & 33.42 & 1.42 & 2.58 & 38.92 & 101.40 & 77.30 & 106.70 & 20.95 & 48.40 & 0.31 & 19.00 \\
All genotypes (n=74) & 29.89 & 1.20 & 2.68 & 37.84 & 121.71 & 79.72 & 191.07 & 23.60 & 67.64 & 0.27 & 21.50 \\
\hline
\end{tabular}

Table 3 Recommended rice genotypes for use in high yielding environments. Mean of major physiological [Photosynthesis (Pn, $\mu \mathrm{mol} \mathrm{m} \mathrm{m}^{-2} \mathrm{~s}^{-1}$ ), Stomatal conductance (Cond, mol m $\mathrm{m}^{-2} \mathrm{~s}^{-1}$ ), intrinsic water use efficiency (iWUE, $\mu \mathrm{mol} \mathrm{m}^{-2} \mathrm{~s}^{-1} / \mathrm{mmol} \mathrm{H}_{2} \mathrm{O} \mathrm{m} \mathrm{m}^{-2} \mathrm{~s}^{-1}$ ), and total chlorophyll (Chl, $\mu \mathrm{g} \mathrm{cm}^{-2}$ )], morphological (days to heading (DH, days), plant height (PHT, cm) and shoot dry weight (SHW, g per plant)], and yield-related [panicle length (PN, cm), grain yield (GY, g per plant) and harvest index (HI, plant basis)] traits in non-stress conditions averaged across years are shown along with additive response indices (ARI) for selected genotypes. 